\title{
Physiologic Implications of Reactive Oxygen Species Production by Mitochondrial Complex I Reverse Electron Transport
}

\author{
John O. Onukwufor ${ }^{1}$, Brandon J. Berry ${ }^{2}$ and Andrew P. Wojtovich ${ }^{1,2, *}$ \\ 1 Department of Anesthesiology and Perioperative Medicine, University of Rochester Medical Center, \\ Rochester, NY 14642, USA \\ 2 Department of Pharmacology and Physiology, University of Rochester Medical Center, Rochester, NY 14642, \\ USA \\ * Correspondence: Andrew_wojtovich@urmc.rochester.edu; Tel.: +585-275-4613
}

Received: 27 June 2019; Accepted: 2 August 2019; Published: 6 August 2019

\begin{abstract}
Mitochondrial reactive oxygen species (ROS) can be either detrimental or beneficial depending on the amount, duration, and location of their production. Mitochondrial complex I is a component of the electron transport chain and transfers electrons from NADH to ubiquinone. Complex I is also a source of ROS production. Under certain thermodynamic conditions, electron transfer can reverse direction and reduce oxygen at complex I to generate ROS. Conditions that favor this reverse electron transport (RET) include highly reduced ubiquinone pools, high mitochondrial membrane potential, and accumulated metabolic substrates. Historically, complex I RET was associated with pathological conditions, causing oxidative stress. However, recent evidence suggests that ROS generation by complex I RET contributes to signaling events in cells and organisms. Collectively, these studies demonstrate that the impact of complex I RET, either beneficial or detrimental, can be determined by the timing and quantity of ROS production. In this article we review the role of site-specific ROS production at complex I in the contexts of pathology and physiologic signaling.
\end{abstract}

Keywords: reactive oxygen species; mitochondrial complex I; reverse electron transport; superoxide; hydrogen peroxide; ischemia reperfusion injury; oxidative damage

\section{Introduction}

Mitochondria are a major source of reactive oxygen species (ROS) production in cells. ROS can be produced during cellular respiration [1,2], where electrons pass directly onto oxygen instead of the next electron carrier in the electron transport chain (ETC) [2-5]. There are many antioxidant systems that detoxify ROS [6]. Under certain conditions, however, such as damage to the ETC or during ischemia reperfusion injury, the amount of ROS produced overwhelms the cellular defense systems resulting in oxidative stress [2,3,7]. For many years ROS have been associated only with oxidative stress, however, it is now accepted that ROS play a role in cellular signaling as well [7-12]. Determining what factors make ROS beneficial or detrimental is an active area of research [13]. Much like the second messenger calcium, the effect of ROS can be determined by many factors including how much, when, and where ROS are produced. There are many sites of ROS generation in mitochondria $[1,2,14-16]$ each of which is differentially sensitive to cellular conditions [17]. However, our understanding of how site-specific ROS production contributes to physiology remains limited. Here we will focus on ROS generated at mitochondrial complex I of the ETC. Complex I can generate ROS through reverse electron transfer (RET) under a variety of metabolic conditions, many of which are associated with pathology $[2,12,18,19]$. However, recent studies suggest that complex I ROS generation by RET can have physiologic roles [12,20-24]. 


\section{Complex I ROS Generation}

\subsection{Complex I Function and ROS Production}

Mitochondrial complex I (NADH:ubiquinone oxidoreductase) is a large multimeric protein complex and a member of the ETC [25-28]. Complex I is comprised of a hydrophobic section located in the inner membrane and a hydrophilic section in the matrix (Figure 1). Complex I transfers two electrons from NADH to ubiquinone $(\mathrm{Q})$ and pumps protons into the intermembrane space $[27,29]$. The hydrophilic section of complex I catalyzes the oxidation of NADH at the flavin mononucleotide (FMN) containing subunit. Electrons are then passed through a series of iron-sulfur clusters to reduce $\mathrm{Q}$ to ubiquinol $\left(\mathrm{QH}_{2}\right)$ at the $\mathrm{Q}$ binding site $[26,27]$. $\mathrm{QH}_{2}$ can transfer electrons to complex III, which are eventually passed onto oxygen at complex IV to form water [27,29]. During this process, an electron can reduce oxygen to generate superoxide $\left(\mathrm{O}_{2} \bullet^{-}\right)$instead of continuing down the ETC. $\mathrm{O}_{2} \bullet^{-}$can be converted to hydrogen peroxide $\left(\mathrm{H}_{2} \mathrm{O}_{2}\right)$ through spontaneous dismutation or enzymatically via superoxide dismutase (SOD) [2]. There are many sites of ROS production in mitochondria, and complex I can generate ROS either through forward electron transfer (NADH to $\mathrm{Q}$ ) or reverse electron transfer $\left(\mathrm{QH}_{2}\right.$ to $\left.\mathrm{NAD}^{+}\right)$[30]. Sites of $\mathrm{O}_{2} \bullet^{-}$generation within complex I include the FMN group, iron-sulfur clusters, and the $\mathrm{Q}$ binding site [31-35]. The FMN and $\mathrm{Q}$ sites are relatively accessible to the mitochondrial matrix. These locations have high probabilities of electrons leaking from the ETC and reducing oxygen to $\mathrm{O}_{2} \bullet^{-}[26,27]$. Additionally, each ROS production site within complex I has a different sensitivity to oxygen concentration, such that changes in the local oxygen levels can affect the site's contribution to ROS production [17].

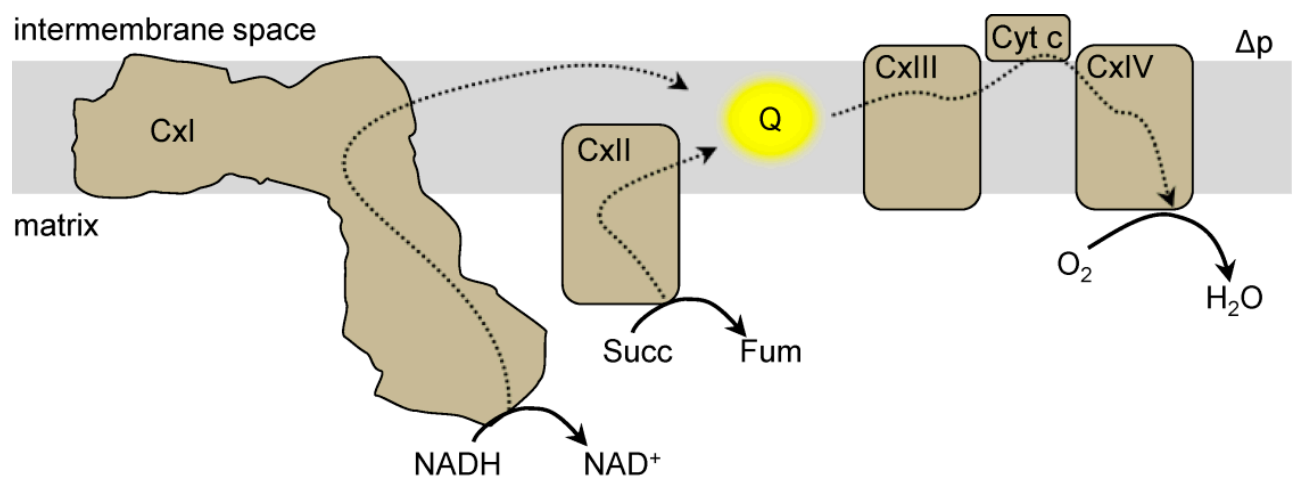

Figure 1. Mitochondrial electron transport chain. The electron transport chain (ETC) is located in the mitochondrial inner membrane. Electrons (dashed lines) from reducing equivalents (e.g., NADH) enter the ETC at complex I (CxI) or complex II (CxII) and reduce the ubiquinone pool (Q, yellow). Electrons are then transferred from $\mathrm{QH}_{2}$ to complex III (CxIII), to cytochrome c (Cyt c) and ultimately onto oxygen $\left(\mathrm{O}_{2}\right)$ at complex IV (CxIV). During this process protons are pumped (not shown) to generate a protonmotive force $(\Delta p)$ which is comprised of a membrane potential and a proton concentration gradient.

\subsection{Protonmotive Force $(\Delta p)$ and Complex I ROS}

The mitochondrial protonmotive force $(\Delta \mathrm{p})$ regulates RET ROS production. The $\Delta \mathrm{p}$ is composed of two potential energies-a proton concentration gradient $(\Delta \mathrm{pH})$ and a charge separation known as the membrane potential $\left(\Delta \psi_{\mathrm{m}}\right)$ [35]. Under normal conditions, the $\Delta \psi_{\mathrm{m}}$ is the major component of the $\Delta \mathrm{p}$ [2]. During an energy demand mitochondria use the $\Delta \mathrm{p}$ to produce ATP, and ROS generation is low [36]. Likewise, protonophores, such as FCCP or DNP, dissipate the $\Delta \mathrm{p}$ and decrease complex I ROS production $[35,37,38]$. At rest conditions, when the $\Delta \mathrm{p}$ is relatively high, ROS production is higher [35]. Therefore, a high $\Delta \mathrm{p}$ is associated with a large amount of complex I ROS generation, and that decreasing the $\Delta \mathrm{p}$ will inhibit complex I ROS production. However, it is unknown whether $\Delta \mathrm{pH}$ and $\Delta \psi_{\mathrm{m}}$ have different contributions to ROS production, or if total $\Delta \mathrm{p}$ is all that matters. 
To determine the contribution of $\Delta \mathrm{pH}$ and $\Delta \psi_{\mathrm{m}}$ to complex I ROS, ion transporters were used to experimentally test each parameter. For example, nigericin lowers $\Delta \mathrm{pH}$ and increases $\Delta \psi_{\mathrm{m}}$ to maintain $\Delta \mathrm{p}$ [35]. Under these conditions, complex I ROS decreased suggesting that complex I ROS is driven by a high $\Delta \mathrm{pH}$ [35]. Similarly, phosphate carrier activity decreased the $\Delta \mathrm{pH}$ and ROS production [35]. Recently, however, using both isolated heart and brain mitochondria, increasing the $\Delta \mathrm{pH}$ and decreasing the $\Delta \psi_{\mathrm{m}}$ simultaneously using a potassium ionophore was concomitant with decreased ROS production [38]. Then using nigericin to perform the reverse experiment (decrease the $\Delta \mathrm{pH}$ and increase the $\Delta \psi_{\mathrm{m}}$ ), increased ROS production was observed. Importantly, these changes were associated with changing $\mathrm{pH}$ levels [38], suggesting that the absolute $\mathrm{pH}$, rather than the $\Delta \mathrm{pH}$ across the inner membrane is responsible for the high complex I ROS production [38].

\subsection{Redox Ratios and Complex I ROS}

The redox statuses of the $\mathrm{QH}_{2} / \mathrm{Q}$ and $\mathrm{NADH} / \mathrm{NAD}^{+}$ratios are also major determinants of the amount of ROS produced at complex I. For example, when mitochondria are making ATP the $\mathrm{NADH} / \mathrm{NAD}^{+}$ratio is low and ROS production is also low [2]. Conversely, a high NADH/NAD ${ }^{+}$or $\mathrm{QH}_{2} / \mathrm{Q}$ ratio is associated with a high level of $\mathrm{ROS}$ production $[2,39,40]$. In conclusion, there are various factors that control the production of ROS and many of these factors are interconnected. For example, changes in the $\Delta \mathrm{p}$ can change redox ratios. Therefore, altering one of these factors in vivo can lead to metabolic changes and introduce confounding factors.

\section{Mitochondrial Complex I Reverse Electron Transfer (RET)}

The electron flow in complex I is described in two modes-forward and reverse electron transfer (Figure 2). Under conditions of normal respiration, forward electron transfer (Figure 2a) is the energetically favored complex I-mediated transfer of electrons from NADH to Q. Reverse electron transfer (RET) (Figure 2b) is the backward transfer of electrons from $\mathrm{QH}_{2}$ to $\mathrm{NAD}^{+}[2,12]$. Under normal conditions, RET is energetically uphill and requires a high $\Delta \mathrm{p}$ and $\mathrm{QH}_{2} / \mathrm{Q}$ ratio [30,41,42]. RET is not tissue or organ specific, as it occurs in mitochondria from different tissues [17,33,35,39,42,43]. In addition, though RET was first observed under conditions of succinate respiration in isolated mitochondria, it is not linked solely to this condition. Mitochondria fueled with fatty acids or $\alpha$-glycerophosphate to reduce $Q$ can undergo RET $[1,21]$, suggesting that RET can be influenced by multiple metabolic pathways.

RET is distinguished from other mechanisms of complex I ROS generation through the use of inhibitors. RET generation of ROS is inhibited by $Q$ binding site inhibitors, such as rotenone [35,42,44]. The specific site responsible for RET ROS production within complex I (e.g., FMN site or Q binding site) is debated $[1,2,35,44,45]$, but all of the likely sites of RET ROS production are located in the mitochondrial matrix [44]. However, current $\mathrm{O}_{2} \bullet^{-}$detection methods lack spatial resolution to precisely distinguish matrix vs. IMS ROS production [26,27]. For example, biosensors, which can be targeted to the matrix or intermembrane space, respond to the membrane permeable $\mathrm{H}_{2} \mathrm{O}_{2}$, not $\mathrm{O}_{2} \bullet^{-}$. Mitochondrial ROS plays a role in cell signaling yet, until recently, the importance of RET ROS in modulating physiologic processes has been overlooked. Since the conditions required for RET (high $\Delta p$ and $\mathrm{QH}_{2} / \mathrm{Q}$ ratio) are not often present in physiologic circumstances, RET has been largely associated with pathologic conditions $[41,42,46]$. New studies are demonstrating a role for RET generated ROS in physiologic processes $[1,2,12,20,21,33,47]$. 
(a) Forward electron transfer

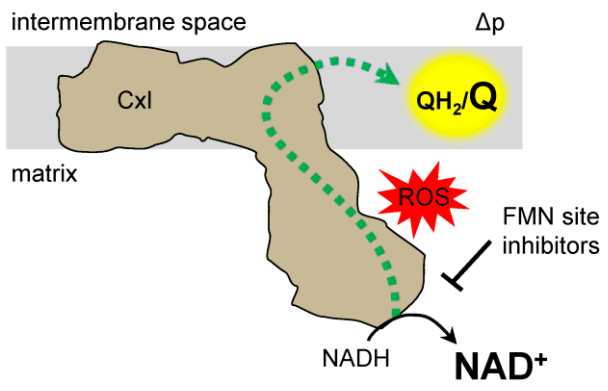

(b) Reverse electron transfer

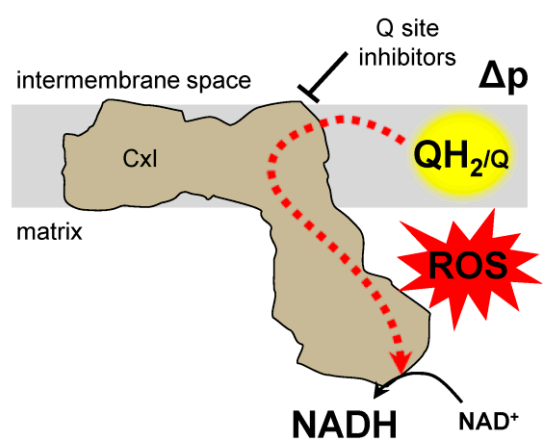

Figure 2. Complex I electron transfer. (a) Forward electron transfer. Electrons (dashed lines) are transferred from NADH to ubiquinone (Q) resulting in ubiquinol $\left(\mathrm{QH}_{2}\right)$. These conditions can generate reactive oxygen species (ROS). The addition of FMN site inhibitors prevent, while $\mathrm{Q}$ binding site inhibitors enhance complex I forward electron transfer generated ROS. (b) Reverse electron transfer (RET). Electrons from ubiquinol $\left(\mathrm{QH}_{2}\right)$ are transferred to $\mathrm{NAD}^{+}$and generate ROS. Both $\mathrm{Q}$ binding site and FMN binding site inhibitors suppress RET generated ROS. $\triangle \mathrm{p}$, protonmotive force; FMN, flavin mononucleotide.

\section{Detecting and Modulating RET ROS Generation}

\subsection{Detecting RET}

RET generates $\mathrm{O}_{2} \bullet^{-}$, which can dismutate to $\mathrm{H}_{2} \mathrm{O}_{2}$, both of which are commonly measured as an output of RET [2]. Extensive analysis of ROS detection methods are reviewed elsewhere [48,49]. Here, we will focus on detection methods that relate to measurements of physiologic RET. $\mathrm{O}_{2} \bullet^{-}$is commonly measured using dihydroethidium (DHE) or mitoSOX (i.e. mitochondria-targeted DHE) [50-52]. DHE can be oxidized through many mechanisms to yield a range of oxidation products. Of the two fluorescent DHE oxidation products, ethidium $\left(\mathrm{E}^{+}\right)$and 2-hydroxyethidium $\left(2-\mathrm{OHE}^{+}\right)$, only 2-OHE ${ }^{+}$ is a selective marker of $\mathrm{O}_{2} \bullet^{-}$[53]. The spectral overlap of $\mathrm{E}^{+}$and $2-\mathrm{OHE}^{+}$and their propensity to intercalate DNA limit the interpretation of fluorescent measurements of $\mathrm{O}_{2} \bullet^{-}$as a readout for RET [53]. To accurately detect $\mathrm{O}_{2} \bullet^{-}$using DHE, the oxidation products should be separated and quantified using HPLC [50-52,54]. Recent advances minimized concerns by modifying structural features of mitoSOX to create mitoNeoD [55], which may limit the confounding factors associated with DHE fluorescence readouts as a measure of RET generated $\mathrm{O}_{2} \bullet^{-}$in vivo [55].

An alternative way to assess complex I RET ROS is to measure $\mathrm{H}_{2} \mathrm{O}_{2}$ using Amplex Red, which in the presence of horseradish peroxidase will react with $\mathrm{H}_{2} \mathrm{O}_{2}$ to give the fluorescent product resorufin [2]. While the use of Amplex Red is well established, studies are generally limited to isolated mitochondria. In vivo studies use ROS biosensors targeted to specific cellular regions or compartments to measure $\mathrm{H}_{2} \mathrm{O}_{2}$ [56-60]. The oxidation of biosensors such as HyPer or redox-sensitive GFP-based probes results in a reversible change in fluorescent signal [61,62]. Like most fluorescent proteins, however, biosensors can be sensitive to $\mathrm{pH}$ and require appropriate control experiments [61]. For example, the $\mathrm{pH}$ gradient across the mitochondrial inner membrane can confound interpretation of ROS readouts when comparing a biosensor signal in the mitochondrial matrix to the intermembrane space or cytosol because of $\mathrm{pH}$ differences. Advances in biosensors are increasing the dynamic range and sensitivity to $\mathrm{H}_{2} \mathrm{O}_{2}$ while limiting the influence of $\mathrm{pH}$ [61].

\subsection{Modulating RET}

In addition to detecting RET, ROS production can be modulated both pharmacologically with $\mathrm{Q}$ site inhibitors, and genetically through expression of exogenous electron transfer systems. RET ROS production can be differentiated from forward electron transfer by using rotenone. $\mathrm{RETO}_{2} \bullet^{-}$production is inhibited by rotenone, where forward electron transfer ROS production is not. Another way to 
probe $\mathrm{RET}$ is by manipulating the $\mathrm{QH}_{2} / \mathrm{Q}$ ratio to influence the rate of complex I ROS production [2]. This approach is implemented by using exogenous enzymes to mimic mitochondrial electron transfer. Expression of Ciona intestinalis alternative oxidase (AOX) and the yeast NADH dehydrogenase (NDI1) is a novel approach to control the $\mathrm{QH}_{2} / \mathrm{Q}$ ratio (Figure 3) [20,21]. AOX is a cyanide-insensitive oxidase that transfers electrons from $\mathrm{QH}_{2}$ to oxygen (Figure 3b). The expression of AOX can decrease the $\mathrm{QH}_{2} / \mathrm{Q}$ ratio [63]. Characterization of $\mathrm{AOX}$ in plants suggests that it is active only once the $\mathrm{QH}_{2} / \mathrm{Q}$ ratio reaches a threshold, suggesting a regulatory switch [64]. NDI1 is a rotenone-insensitive NADH dehydrogenase that transfers electrons from $\mathrm{NADH}$ to $\mathrm{Q}$, resulting in a high $\mathrm{QH}_{2} / \mathrm{Q}$ ratio (Figure 3a) [65]. Together AOX and NDI1 can bypass components of the ETC to directly alter the $\mathrm{QH}_{2} / \mathrm{Q}$ ratio. However, there are many electron entry points to the $\mathrm{Q}$ pool, such as complex II, dihydroorotate dehydrogenase, electron transfer flavoprotein-ubiquinone oxidoreductase, and glycerol-3-phosphate dehydrogenase. AOX expression does not affect development in Drosophila melanogaster and suggests that AOX expression is not detrimental $[63,66]$. However, it is unclear how the AOX-mediated changes in the $\mathrm{QH}_{2} / \mathrm{Q}$ ratio can impact metabolism and subsequently, ROS production at other mitochondrial sites. Recently, AOX expression was shown to decrease male fertility in Drosophila melanogaster [67]. While the role of ROS in mediating fertility is unclear, it demonstrates that AOX can influence physiologic processes. Additionally, AOX activity will consume oxygen and can effect ROS production at the substrate level, since altering local oxygen concentrations can impact ROS production rates [68]. Overall, multiple approaches and careful interpretation are warranted to determine the role of complex I RET generated ROS.

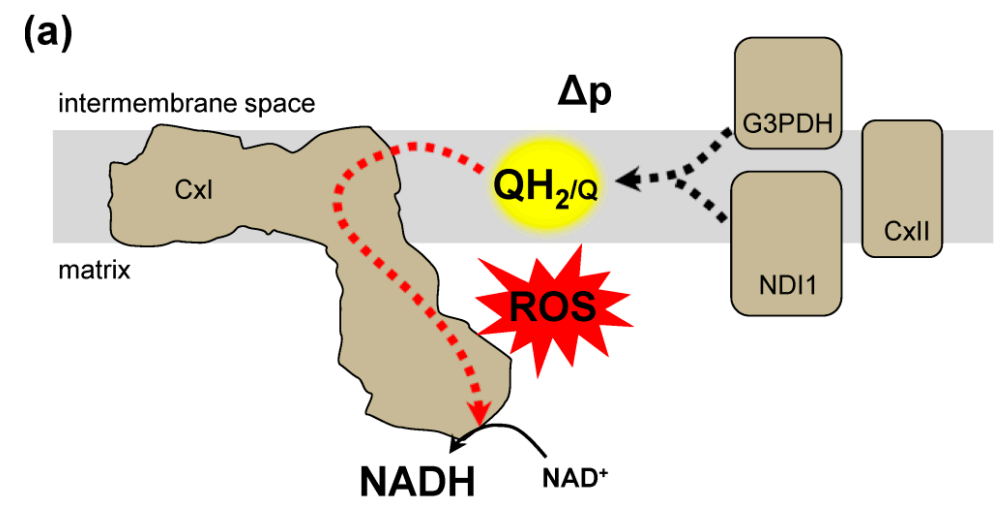

(b)

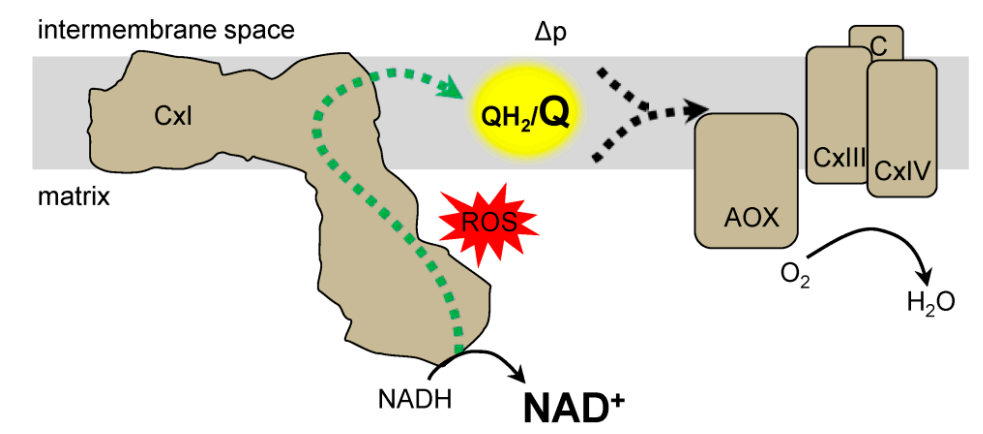

Figure 3. Genetic approaches to alter the $\mathrm{QH}_{2} / \mathrm{Q}$ ratio and modify complex I reverse electron transfer. (a) The expression of NDI1 in the mitochondria can result in the reduction of the Q pool. NDI1 transfers electrons from $\mathrm{NADH}$ to $\mathrm{Q}$ resulting in $\mathrm{QH}_{2}$. The resulting conditions favor reverse electron transfer generation of ROS. Other proteins that can increase the $\mathrm{QH}_{2} / \mathrm{Q}$ ratio include complex II (CxII) or glycerol-3-phosphate dehydrogenase (G3PDH). (b) Expression of alternative oxidase (AOX) decreases the $\mathrm{QH}_{2} / \mathrm{Q}$ ratio. AOX transfers from $\mathrm{QH}_{2}$ to $\mathrm{O}_{2}$ to produce water $\left(\mathrm{H}_{2} \mathrm{O}\right)$. Together the activity of complex III (CxIII), cytochrome c (C), and complex IV (CxIV) also decrease the $\mathrm{QH}_{2} / \mathrm{Q}$ ratio resulting in conditions that do not favor RET formation of ROS. 


\section{RET Generated ROS in Pathology}

Most of what is known about RET was discovered in models of ischemia reperfusion (IR) injury. The conditions for RET described herein occur in many pathologic situations, but we will focus IR injury. Loss of blood flow to tissue (ischemia) and subsequent reestablishment (reperfusion) results in IR injury. In mitochondria, depleted oxygen during ischemia combined with its rapid restoration at reperfusion cause oxidative damage to tissue [69]. This damage can occur from ROS generated in several places in mitochondria [70]. At complex I, metabolic substrates that accumulate during ischemia [18] are rapidly oxidized at reperfusion, causing damage. Specifically, accumulated succinate drives RET and ROS production, implicating complex I ROS in the oxidative damage from IR injury (Figure 4a) [19].

(a) (ischemia)

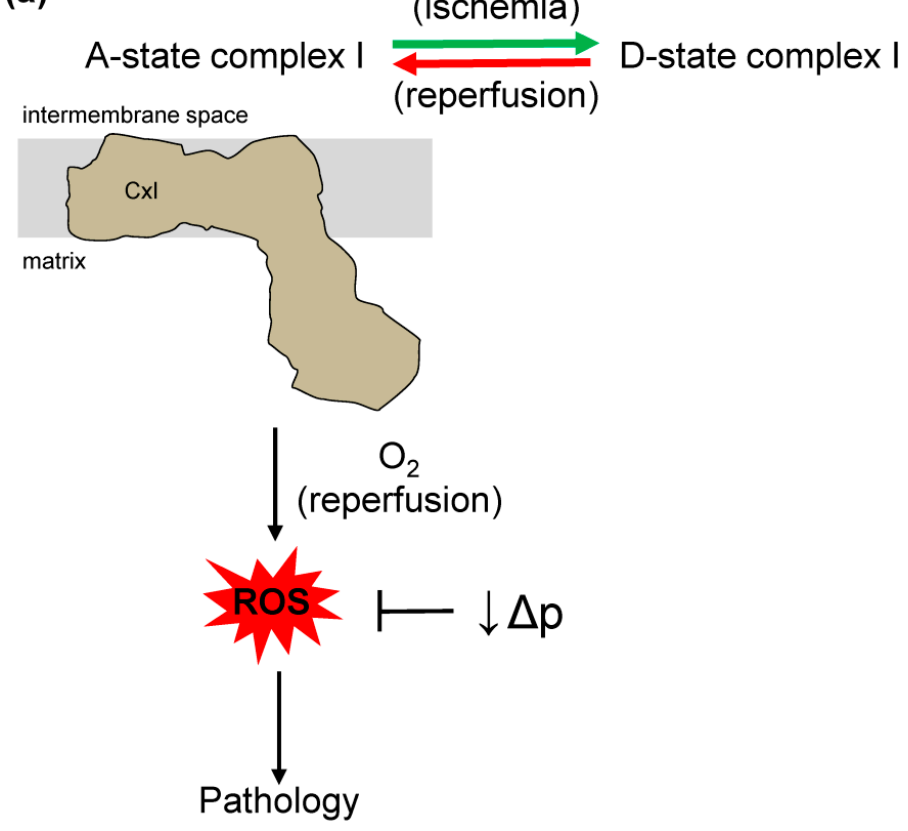

(b)

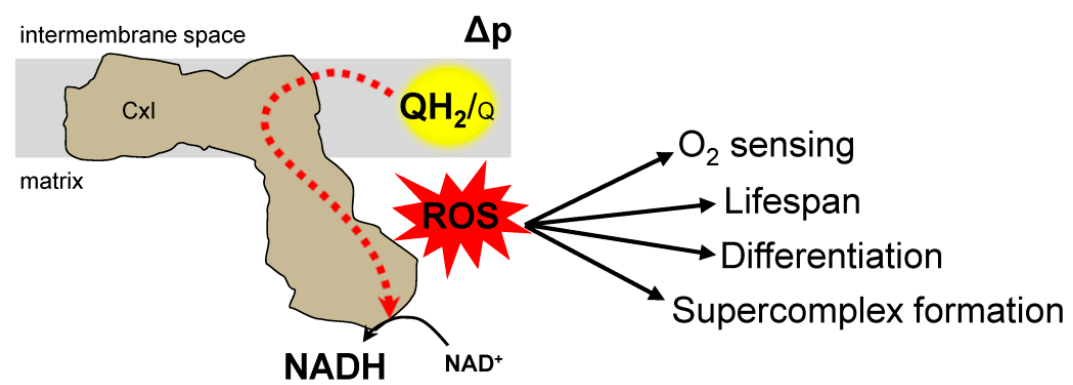

Figure 4. Dual role of complex I reverse electron transfer in pathology and physiology. (a) Complex I (CxI) reverse electron transfer (RET) in pathology. Factors that affect RET in ischemia reperfusion (IR) injury. During ischemia, succinate accumulation drives RET at complex II forcing electrons to complex I, where ROS is subsequently overproduced. Complex I has two states, active (A) and dormant (D). Ischemia drives an A-form that transition to D-form. During reperfusion D-form transition back to A-form generating reactive oxygen species (ROS) that causes IR injury. The mitochondrial protonmotive force $(\Delta \mathrm{p})$ is a main driving force for RET. Therefore, decreasing the $\Delta \mathrm{p}$ removes a main driver of RET and ROS production at reperfusion. (b) Complex I reverse electron transfer contributes to diverse physiologic processes. The site-specific ROS production has a role in oxygen $\left(\mathrm{O}_{2}\right)$ sensing, lifespan extension, cell differentiation, and supercomplex formation. 
Complex I has enzymatically active (A) and dormant (D) states under different conditions [71]. The A state has catalytic NADH/Q oxidoreductase activity, however, the D state is inhibited and more susceptible to oxidative modification in vitro [72,73]. During ischemia there is a reversible transition from the A to the D state. This transition is hypothesized to be a physiologic mechanism to limit ROS production at reperfusion, as the D state makes less ROS by RET than the A state [74]. Oxidative damage at reperfusion is driven by RET succinate oxidation at functional complex I in the A state [30]. Ischemic transition of complex I to the D state could be a preparation for reperfusion, serving to inhibit complex I activity and RET (Figure 4a). In depth characterization of complex I A/D transition could yield targeted therapies to prevent damage. Targeting specific sites of complex I ROS formation could also yield targeted therapy.

During RET, one of the ROS production sites in complex I is the Q binding site (IQ) [75]. There are many small molecules called suppressors of complex I site I(Q) electron leak (S1QELs), that inhibit complex I at this site, preventing ROS production and protecting against IR injury $[70,76,77]$. The onset of IR events is unpredictable, however. Using drugs to protect against IR injury would be most clinically useful administered at or after reperfusion, when it is clear intervention is needed. In support of this notion, metformin, an FDA approved diabetes drug, can inhibit complex I at reperfusion and limit IR injury in animal and cell models [78]. Similarly, genetic knockout of a complex I subunit results in altered ROS levels and decreased susceptibility to IR injury [79]. These results suggest diminished complex I activity, and resulting diminished RET activity at reperfusion, is protective against IR. These data are in line with the proposed beneficial role of D state complex I preventing oxidative damage at reperfusion. While preemptively inhibiting complex I ROS production before an ischemic event protects against IR injury, the inhibition could impair beneficial oxidative signaling, as discussed in the following section. The dual roles of ROS damage and signaling may be the reason for the failure of global antioxidant treatments for disease $[80,81]$. Again, targeted approaches to decrease damaging ROS while preserving signaling ROS will be necessary for the successful development of redox medicine. This approach requires in-depth understanding of the molecular mechanisms of RET and complex I function.

Changes in the $\Delta \mathrm{p}$ can also alter RET, where decreased potential results in less ROS production (Figure 4a) [35]. Decreasing both components of the $\Delta \mathrm{p}$ with small-molecule protonophores like FCCP is protective in many models of IR injury [82-84]. The molecular details of these and similar results are unclear but represent a promising targeted approach to understand mechanisms of pathology.

The research summarized here demonstrates how RET and complex I ROS production contribute to IR injury, and shows that clarifying molecular mechanisms will be essential for clinical application. The pathologic events in and around mitochondria during IR are interrelated and coupled to cellular metabolism [36]. Thus, careful experimental approaches will isolate RET to discern mechanisms in pathology.

\section{RET Generated ROS in Physiology}

Although RET is involved in pathology, it may have roles in well-coordinated physiological processes that cause cellular adaption (Figure 4b). For example, RET generated ROS is implicated in detecting cellular oxygen levels, cellular differentiation, lifespan extension, and ETC rearrangement [12,20-24].

The ability to sense limited oxygen and initiate a rapid adaptive response is key to cellular survival under low oxygen tensions. One way that an organism senses low oxygen is through the carotid body $[11,22,85]$. The carotid body is a group of cells in the carotid artery responsible for oxygen sensing that contain oxygen-sensitive $\mathrm{K}^{+}$channels. During hypoxia, $\mathrm{K}^{+}$channels are inhibited, leading to cellular depolarization and the release of neurotransmitters, resulting in hyperventilatory activity [22]. Hyperventilation (rapid breathing) is an acute way the body increases oxygen supply to tissues [86]. The precise mechanism through which the carotid body senses low oxygen and activates a response is still unfolding [22], however, RET generated ROS is involved [22,23]. This is 
based on the observation that high carotid body activity following low oxygen tension corresponded with elevated ROS measured by mitoSOX fluorescence in carotid body cells [22]. In addition to mitoSOX, a redox-sensitive fluorescent protein sensor (roGFP) was targeted to the mitochondrial intermembrane space and to the cytosol to measure ROS levels in mice exposed to hypoxia [22]. The levels of $\mathrm{H}_{2} \mathrm{O}_{2}$ were high in the intermembrane space and low in the cytosol. The changes in ROS levels in carotid body cells were sensitive to the loss of Ndufs2, which encodes the complex I ubiquinone binding site, suggesting that ROS originates from complex I [22]. These results highlight the importance of site-specific measurement of ROS [23]. Given that ETC inhibitors other than rotenone can influence carotid body cell oxygen sensing [87], and that other sources of ROS can mediate responses to hypoxia [88], understanding the site-specific nature of complex I ROS in the signaling process is essential. In support of this notion, a recent paper reinforced the oxygen sensing role of Ndufs2 [89].

RET has also been implicated in muscle differentiation [24]. ROS produced at complex I stimulated muscle differentiation in $\mathrm{H} 9 \mathrm{c} 2$ rat cardiac myoblasts [24]. The increased mitochondrial $\mathrm{O}_{2} \bullet^{-}$was measured by mitoSOX fluorescence and was associated with an increase in SOD expression and $\mathrm{H}_{2} \mathrm{O}_{2}$ diffusion to the cytosol, where it stimulated differentiation [24]. Mitochondria-targeted $\mathrm{O}_{2} \bullet^{-}$scavengers, mitoquinone (mitoQ) and mitoTempol suppressed morphological changes, major histocompatibility complex (MHC) expression in myotube formation, muscle creatine kinase (MCK) promoter activity and $\mathrm{H}_{2} \mathrm{O}_{2}$ production, confirming the role of ROS in muscle differentiation. Moreover, the expression of mitochondria-targeted catalase (mCAT) prevented differentiation, implicating the mitochondrial matrix ROS production [24]. Three subunits of complex I were upregulated during muscle differentiation, suggesting that complex I plays a role in $\mathrm{O}_{2} \bullet^{-}$formation [24]. In agreement with these studies, mitochondrial ROS and muscle differentiation were sensitive to rotenone and the knockdown of the complex I subunits Ndufaf1 and Ndufs3 [24]. In addition, a single bout of exercise resulted in increased mitophagy and mitochondrial function in both heart and skeletal muscle [90]. These increases were in part due to the increase in mitochondrial $\mathrm{H}_{2} \mathrm{O}_{2}$ measured using Amplex Red [90]. Similarly, dietary lutein, a carotenoid that aids vision, enhanced the differentiation of SH-SY5Y cells through phosphoinositide-3-kinase signaling, which is triggered by mitochondrial $\mathrm{H}_{2} \mathrm{O}_{2}$ [91]. These results are in line with conditions that favor RET, but a direct role of complex I ROS is unclear.

RET generated ROS also mediates lifespan extension, as observed in flies [20]. The role of RET in lifespan extension was investigated by modulating the redox state of the $\mathrm{QH}_{2} / \mathrm{Q}$ ratio using NDI1 and AOX $[20,92,93]$. The expression of NDI1 altered the steady-state ratio of NADH/NAD ${ }^{+}$, reduced $\mathrm{Q}$, and extended lifespan [92]. In a pharmacologic approach, rotenone (a $\mathrm{Q}$ binding site inhibitor) treatment or knockdown of complex I did not alter the beneficial effects of NDI1 [92], suggesting that NDI1 compensates for endogenous complex I activity in flies [92]. Interestingly, NDI1 does not compensate for lost complex I activity in C. elegans [94,95], suggesting that $\mathrm{QH}_{2} / \mathrm{Q}$ ratio can be differentially regulated in various organisms. In support of this notion is the observation that AOX inhibited the lifespan extension by NDI1 [20]. This indicates that $\mathrm{QH}_{2}$ is at the center of the lifespan extension. In line with this, feeding flies rotenone reduced ROS production in NDI1 mutant flies but not in wildtype flies [20]. Similar results were observed using protonophores to dissipate the $\Delta \mathrm{p}$. This indicates the involvement of complex I RET as the source of NDI1 mediated ROS production that extends lifespan in flies. If the mechanisms are conserved in mammals, manipulation of the $\mathrm{QH}_{2} / \mathrm{Q}$ ratio provides a therapeutic target for the extension lifespan, or for treatment of aging and age-related disease such as IR injury and diabetes [20].

RET can contribute to physiology through changes at the organelle level. During an energy demand the ETC complexes can arrange into supercomplexes, which include groupings of complexes I, III, and IV of the ETC, and their formation is associated with efficient respiratory activity [96]. RET is implicated in the formation of supercomplexes following changes in fuel source, oxygen tension, or stress $[21,96,97]$. When the ETC complexes are fueled through glycolysis, electrons from NADH can increase the $\mathrm{QH}_{2} / \mathrm{Q}$ ratio via complex I. These conditions favor a supercomplex where complex I is associated with complex III $[12,21]$. $\beta$-oxidation can further reduce the $Q$ pool through the added 
contribution of FAD-dependent enzymes. The resulting increased $\mathrm{QH}_{2} / \mathrm{Q}$ ratio is associated with high levels of ROS production and disassociated supercomplexes. Recent work demonstrated that the high $\mathrm{QH}_{2} / \mathrm{Q}$ ratio during $\beta$-oxidation leads to RET produced ROS (Figure 3a) and the localized RET leads to changes in supercomplex formation. The localized ROS were shown to oxidize complex I, resulting in the degradation and dissociation of complex I from the supercomplex [21]. Without a privileged location between complexes I and III, the dissociated complex III is hypothesized to favor electron flux through FAD-dependent sources and limit overall ROS production [21].

Overall, RET ROS production has defined roles in physiology. Understanding the molecular details of RET could provide new mechanisms of physiologic regulation.

\section{Conclusions and Future Directions}

Overall, where ROS are generated can greatly impact the cellular response. As such, ROS are involved in heterogeneous cell processes, ranging from signaling events to death. Our understanding of how RET generated ROS produces specific signals is limited. For example, it is unclear how RET ROS increases lifespan, and the signaling mechanisms involved are not fully elucidated. Further, it is unknown how each of these processes are selective for RET derived ROS. It is also unclear which sites of ROS production within complex I impact physiologic outputs. Answering these questions will help uncover the beneficial effects of site-specific ROS production. Careful experimental design and methods that rigorously measure site-specific RET ROS would increase our knowledge of physiologic RET. Methods of ROS detection are imperfect and are often used incorrectly, confounding interpretations. Focusing on defined molecular outputs of ROS rather than imperfect bulk measurements will advance the field in a complementary way. For example, measuring a specific ROS post-translational modification may be more informative than observing increased or decreased ROS under experimental conditions. This approach is important given the nuances of known microdomain effects [98,99]. The research described here highlights the importance of understanding molecular mechanisms of site-specific ROS production in mitochondria, and serves as a starting point to develop new methods to probe the many facets of ROS physiology.

Author Contributions: Writing-Original draft preparation, J.O.O., B.J.B.; Writing—Review and editing, J.O.O., B.J.B., A.P.W.; Funding acquisition, A.P.W., B.J.B.

Funding: This research was funded by National Institutes of Health, R01 NS092558 to A.P.W., an Institutional Ruth L. Kirschstein National Research Service Award, GM068411 to B.J.B., and an American Heart Association predoctoral fellowship, (18PRE33990054) to B.J.B.

Acknowledgments: We thank the Mitochondrial Group (University of Rochester) for valuable discussions.

Conflicts of Interest: The authors declare no conflict of interest.

\section{References}

1. Adam-Vizi, V.; Chinopoulos, C. Bioenergetics and the formation of mitochondrial reactive oxygen species. Trends Pharmacol. Sci. 2006, 27, 639-645. [CrossRef] [PubMed]

2. Murphy, M.P. How mitochondria produce reactive oxygen species. Biochem. J. 2009, 417, 1-13. [CrossRef] [PubMed]

3. Cadenas, E.; Davies, K.J. Mitochondrial free radical generation, oxidative stress, and aging. Free Radic. Biol. Med. 2000, 29, 222-230. [CrossRef]

4. Radi, R.; Turrens, J.F.; Chang, L.Y.; Bush, K.M.; Crapo, J.D.; Freeman, B.A. Detection of catalase in rat heart mitochondria. J. Biol. Chem. 1991, 266, 22028-22034. [PubMed]

5. Salvi, M.; Battaglia, V.; Brunati, A.M.; La Rocca, N.; Tibaldi, E.; Pietrangeli, P.; Marcocci, L.; Mondovi, B.; Rossi, C.A.; Toninello, A. Catalase takes part in rat liver mitochondria oxidative stress defense. J. Biol. Chem. 2007, 282, 24407-24415. [CrossRef] [PubMed]

6. Imai, H.; Nakagawa, Y. Biological significance of phospholipid hydroperoxide glutathione peroxidase (PHGPx, GPx4) in mammalian cells. Free Radic. Biol. Med. 2003, 34, 145-169. [CrossRef] 
7. Chen, Y.R.; Zweier, J.L. Cardiac mitochondria and reactive oxygen species generation. Circ. Res. 2014, 114, 524-537. [CrossRef] [PubMed]

8. Finkel, T. Signal transduction by reactive oxygen species. J. Cell Biol. 2011, 194, 7-15. [CrossRef] [PubMed]

9. Schieber, M.; Chandel, N.S. ROS function in redox signaling and oxidative stress. Curr. Biol. 2014, 24, R453-R462. [CrossRef] [PubMed]

10. Gao, L.; Gonzalez-Rodriguez, P.; Ortega-Saenz, P.; Lopez-Barneo, J. Redox signaling in acute oxygen sensing. Redox Biol. 2017, 12, 908-915. [CrossRef] [PubMed]

11. Lopez-Barneo, J.; Gonzalez-Rodriguez, P.; Gao, L.; Fernandez-Aguera, M.C.; Pardal, R.; Ortega-Saenz, P. Oxygen sensing by the carotid body: Mechanisms and role in adaptation to hypoxia. Am. J. Physiol. Cell Physiol. 2016, 310, C629-C642. [CrossRef] [PubMed]

12. Scialo, F.; Fernandez-Ayala, D.J.; Sanz, A. Role of Mitochondrial Reverse Electron Transport in ROS Signaling: Potential Roles in Health and Disease. Front. Physiol. 2017, 8, 428. [CrossRef] [PubMed]

13. Di Meo, S.; Reed, T.T.; Venditti, P.; Victor, V.M. Harmful and Beneficial Role of ROS. Oxid. Med. Cell. Longev. 2016, 2016, 7909186. [CrossRef] [PubMed]

14. Turrens, J.F. Mitochondrial formation of reactive oxygen species. J. Physiol. 2003, 552, 335-344. [CrossRef] [PubMed]

15. Andreyev, A.Y.; Kushnareva, Y.E.; Starkov, A.A. Mitochondrial metabolism of reactive oxygen species. Biochem. Biokhimiia 2005, 70, 200-214. [CrossRef]

16. Azzu, V.; Brand, M.D. The on-off switches of the mitochondrial uncoupling proteins. Trends Biochem. Sci. 2010, 35, 298-307. [CrossRef]

17. Hoffman, D.L.; Brookes, P.S. Oxygen sensitivity of mitochondrial reactive oxygen species generation depends on metabolic conditions. J. Biol. Chem. 2009, 284, 16236-16245. [CrossRef]

18. Zhang, J.; Wang, Y.T.; Miller, J.H.; Day, M.M.; Munger, J.C.; Brookes, P.S. Accumulation of Succinate in Cardiac Ischemia Primarily Occurs via Canonical Krebs Cycle Activity. Cell Rep. 2018, 23, 2617-2628. [CrossRef]

19. Chouchani, E.T.; Pell, V.R.; Gaude, E.; Aksentijevic, D.; Sundier, S.Y.; Robb, E.L.; Logan, A.; Nadtochiy, S.M.; Ord, E.N.J.; Smith, A.C.; et al. Ischaemic accumulation of succinate controls reperfusion injury through mitochondrial ROS. Nature 2014, 515, 431-435. [CrossRef]

20. Scialo, F.; Sriram, A.; Fernandez-Ayala, D.; Gubina, N.; Lohmus, M.; Nelson, G.; Logan, A.; Cooper, H.M.; Navas, P.; Enriquez, J.A.; et al. Mitochondrial ROS Produced via Reverse Electron Transport Extend Animal Lifespan. Cell Metab. 2016, 23, 725-734. [CrossRef]

21. Guaras, A.; Perales-Clemente, E.; Calvo, E.; Acin-Perez, R.; Loureiro-Lopez, M.; Pujol, C.; Martinez-Carrascoso, I.; Nunez, E.; Garcia-Marques, F.; Rodriguez-Hernandez, M.A.; et al. The CoQH2/CoQ Ratio Serves as a Sensor of Respiratory Chain Efficiency. Cell Rep. 2016, 15, 197-209. [CrossRef] [PubMed]

22. Fernandez-Aguera, M.C.; Gao, L.; Gonzalez-Rodriguez, P.; Pintado, C.O.; Arias-Mayenco, I.; Garcia-Flores, P.; Garcia-Perganeda, A.; Pascual, A.; Ortega-Saenz, P.; Lopez-Barneo, J. Oxygen Sensing by Arterial Chemoreceptors Depends on Mitochondrial Complex I Signaling. Cell Metab. 2015, 22, 825-837. [CrossRef] [PubMed]

23. Arias-Mayenco, I.; Gonzalez-Rodriguez, P.; Torres-Torrelo, H.; Gao, L.; Fernandez-Aguera, M.C.; Bonilla-Henao, V.; Ortega-Saenz, P.; Lopez-Barneo, J. Acute O2 Sensing: Role of Coenzyme QH2/Q Ratio and Mitochondrial ROS Compartmentalization. Cell Metab. 2018, 28, 145-158. [CrossRef] [PubMed]

24. Lee, S.; Tak, E.; Lee, J.; Rashid, M.A.; Murphy, M.P.; Ha, J.; Kim, S.S. Mitochondrial H2O2 generated from electron transport chain complex I stimulates muscle differentiation. Cell Res. 2011, 21, 817-834. [CrossRef] [PubMed]

25. Carroll, J.; Fearnley, I.M.; Skehel, J.M.; Shannon, R.J.; Hirst, J.; Walker, J.E. Bovine complex I is a complex of 45 different subunits. J. Biol. Chem. 2006, 281, 32724-32727. [CrossRef] [PubMed]

26. Hirst, J. Mitochondrial complex I. Annu. Rev. Biochem. 2013, 82, 551-575. [CrossRef] [PubMed]

27. Hirst, J. Towards the molecular mechanism of respiratory complex I. Biochem. J. 2009, 425, 327-339. [CrossRef] [PubMed]

28. Wirth, C.; Brandt, U.; Hunte, C.; Zickermann, V. Structure and function of mitochondrial complex I. Biochim. Biophys. Acta 2016, 1857, 902-914. [CrossRef] [PubMed]

29. Efremov, R.G.; Sazanov, L.A. Structure of the membrane domain of respiratory complex I. Nature 2011, 476, 414-420. [CrossRef] 
30. Drose, S.; Stepanova, A.; Galkin, A. Ischemic A/D transition of mitochondrial complex I and its role in ROS generation. Biochim. Biophys. Acta 2016, 1857, 946-957. [CrossRef]

31. Genova, M.L.; Ventura, B.; Giuliano, G.; Bovina, C.; Formiggini, G.; Parenti Castelli, G.; Lenaz, G. The site of production of superoxide radical in mitochondrial Complex I is not a bound ubisemiquinone but presumably iron-sulfur cluster N2. FEBS Lett. 2001, 505, 364-368. [CrossRef]

32. Kushnareva, Y.; Murphy, A.N.; Andreyev, A. Complex I-mediated reactive oxygen species generation: Modulation by cytochrome c and NAD(P)+ oxidation-reduction state. Biochem. J. 2002, 368, 545-553. [CrossRef] [PubMed]

33. Liu, Y.; Fiskum, G.; Schubert, D. Generation of reactive oxygen species by the mitochondrial electron transport chain. J. Neurochem. 2002, 80, 780-787. [CrossRef] [PubMed]

34. Turrens, J.F.; Boveris, A. Generation of superoxide anion by the NADH dehydrogenase of bovine heart mitochondria. Biochem. J. 1980, 191, 421-427. [CrossRef] [PubMed]

35. Lambert, A.J.; Brand, M.D. Superoxide production by NADH:ubiquinone oxidoreductase (complex I) depends on the $\mathrm{pH}$ gradient across the mitochondrial inner membrane. Biochem. J. 2004, 382, 511-517. [CrossRef] [PubMed]

36. Berry, B.J.; Trewin, A.J.; Amitrano, A.M.; Kim, M.; Wojtovich, A.P. Use the Protonmotive Force: Mitochondrial Uncoupling and Reactive Oxygen Species. J. Mol. Biol. 2018, 430, 3873-3891. [CrossRef] [PubMed]

37. Votyakova, T.V.; Reynolds, I.J. DeltaPsi(m)-Dependent and -independent production of reactive oxygen species by rat brain mitochondria. J. Neurochem. 2001, 79, 266-277. [CrossRef] [PubMed]

38. Komlodi, T.; Geibl, F.F.; Sassani, M.; Ambrus, A.; Tretter, L. Membrane potential and delta pH dependency of reverse electron transport-associated hydrogen peroxide production in brain and heart mitochondria. J. Bioenerg. Biomembr. 2018, 50, 355-365. [CrossRef]

39. Kussmaul, L.; Hirst, J. The mechanism of superoxide production by NADH:ubiquinone oxidoreductase (complex I) from bovine heart mitochondria. Proc. Natl. Acad. Sci. USA 2006, 103, 7607-7612. [CrossRef]

40. Kudin, A.P.; Bimpong-Buta, N.Y.; Vielhaber, S.; Elger, C.E.; Kunz, W.S. Characterization of superoxide-producing sites in isolated brain mitochondria. J. Biol. Chem. 2004, 279, 4127-4135. [CrossRef]

41. Chance, B. The interaction of energy and electron transfer reactions in mitochondria. II. General properties of adenosine triphosphate-linked oxidation of cytochrome and reduction of pyridine nucleotide. J. Biol. Chem. 1961, 236, 1544-1554. [PubMed]

42. Chance, B.; Hollunger, G. The interaction of energy and electron transfer reactions in mitochondria. I. General properties and nature of the products of succinate-linked reduction of pyridine nucleotide. J. Biol. Chem. 1961, 236, 1534-1543. [PubMed]

43. Stepanova, A.; Kahl, A.; Konrad, C.; Ten, V.; Starkov, A.S.; Galkin, A. Reverse electron transfer results in a loss of flavin from mitochondrial complex I: Potential mechanism for brain ischemia reperfusion injury. J. Cereb. Blood Flow Metab. Off. J. Int. Soc. Cereb. Blood Flow Metab. 2017, 37, 3649-3658. [CrossRef] [PubMed]

44. Hirst, J.; King, M.S.; Pryde, K.R. The production of reactive oxygen species by complex I. Biochem. Soc. Trans. 2008, 36, 976-980. [CrossRef] [PubMed]

45. Lambert, A.J.; Buckingham, J.A.; Boysen, H.M.; Brand, M.D. Diphenyleneiodonium acutely inhibits reactive oxygen species production by mitochondrial complex I during reverse, but not forward electron transport. Biochim. Biophys. Acta 2008, 1777, 397-403. [CrossRef] [PubMed]

46. Shabalina, I.G.; Nedergaard, J. Mitochondrial ('mild') uncoupling and ROS production: Physiologically relevant or not? Biochem. Soc. Trans. 2011, 39, 1305-1309. [CrossRef] [PubMed]

47. Pell, V.R.; Chouchani, E.T.; Frezza, C.; Murphy, M.P.; Krieg, T. Succinate metabolism: A new therapeutic target for myocardial reperfusion injury. Cardiovasc. Res. 2016, 111, 134-141. [CrossRef] [PubMed]

48. Dikalov, S.I.; Harrison, D.G. Methods for detection of mitochondrial and cellular reactive oxygen species. Antioxid. Redox Signal. 2014, 20, 372-382. [CrossRef]

49. Hardy, M.; Zielonka, J.; Karoui, H.; Sikora, A.; Michalski, R.; Podsiadly, R.; Lopez, M.; Vasquez-Vivar, J.; Kalyanaraman, B.; Ouari, O. Detection and Characterization of Reactive Oxygen and Nitrogen Species in Biological Systems by Monitoring Species-Specific Products. Antioxid. Redox Signal. 2018, 28, 1416-1432. [CrossRef]

50. Michalski, R.; Michalowski, B.; Sikora, A.; Zielonka, J.; Kalyanaraman, B. On the use of fluorescence lifetime imaging and dihydroethidium to detect superoxide in intact animals and ex vivo tissues: A reassessment. Free Radic. Biol. Med. 2014, 67, 278-284. [CrossRef] 
51. Zielonka, J.; Hardy, M.; Kalyanaraman, B. HPLC study of oxidation products of hydroethidine in chemical and biological systems: Ramifications in superoxide measurements. Free Radic. Biol. Med. 2009, 46, 329-338. [CrossRef] [PubMed]

52. Kalyanaraman, B.; Hardy, M.; Podsiadly, R.; Cheng, G.; Zielonka, J. Recent developments in detection of superoxide radical anion and hydrogen peroxide: Opportunities, challenges, and implications in redox signaling. Arch. Biochem. Biophys. 2017, 617, 38-47. [CrossRef] [PubMed]

53. Zielonka, J.; Kalyanaraman, B. Hydroethidine- and MitoSOX-derived red fluorescence is not a reliable indicator of intracellular superoxide formation: Another inconvenient truth. Free Radic. Biol. Med. 2010, 48, 983-1001. [CrossRef] [PubMed]

54. Barnett, M.E.; Baran, T.M.; Foster, T.H.; Wojtovich, A.P. Quantification of light-induced miniSOG superoxide production using the selective marker, 2-hydroxyethidium. Free Radic. Biol. Med. 2018, 116, 134-140. [CrossRef] [PubMed]

55. Shchepinova, M.M.; Cairns, A.G.; Prime, T.A.; Logan, A.; James, A.M.; Hall, A.R.; Vidoni, S.; Arndt, S.; Caldwell, S.T.; Prag, H.A.; et al. MitoNeoD: A Mitochondria-Targeted Superoxide Probe. Cell Chem. Biol. 2017, 24, 1285-1298 e1212. [CrossRef]

56. Ermakova, Y.G.; Bilan, D.S.; Matlashov, M.E.; Mishina, N.M.; Markvicheva, K.N.; Subach, O.M.; Subach, F.V.; Bogeski, I.; Hoth, M.; Enikolopov, G.; et al. Red fluorescent genetically encoded indicator for intracellular hydrogen peroxide. Nat. Commun. 2014, 5, 5222. [CrossRef]

57. Cheng, W.Y.; Larson, J.M.; Samet, J.M. Monitoring intracellular oxidative events using dynamic spectral unmixing microscopy. Methods 2014, 66, 345-352. [CrossRef]

58. Bertolotti, M.; Bestetti, S.; Garcia-Manteiga, J.M.; Medrano-Fernandez, I.; Dal Mas, A.; Malosio, M.L.; Sitia, R. Tyrosine kinase signal modulation: A matter of H2O2 membrane permeability? Antioxid. Redox Signal. 2013, 19, 1447-1451. [CrossRef]

59. Markvicheva, K.N.; Bilan, D.S.; Mishina, N.M.; Gorokhovatsky, A.Y.; Vinokurov, L.M.; Lukyanov, S.; Belousov, V.V. A genetically encoded sensor for $\mathrm{H} 2 \mathrm{O} 2$ with expanded dynamic range. Bioorg. Med. Chem. 2011, 19, 1079-1084. [CrossRef]

60. Belousov, V.V.; Fradkov, A.F.; Lukyanov, K.A.; Staroverov, D.B.; Shakhbazov, K.S.; Terskikh, A.V.; Lukyanov, S. Genetically encoded fluorescent indicator for intracellular hydrogen peroxide. Nat. Methods 2006, 3, 281-286. [CrossRef]

61. Bilan, D.S.; Belousov, V.V. HyPer Family Probes: State of the Art. Antioxid. Redox Signal. 2016, 24, 731-751. [CrossRef] [PubMed]

62. Roma, L.P.; Deponte, M.; Riemer, J.; Morgan, B. Mechanisms and Applications of Redox-Sensitive Green Fluorescent Protein-Based Hydrogen Peroxide Probes. Antioxid. Redox Signal. 2018, 29, 552-568. [CrossRef] [PubMed]

63. Fernandez-Ayala, D.J.; Sanz, A.; Vartiainen, S.; Kemppainen, K.K.; Babusiak, M.; Mustalahti, E.; Costa, R.; Tuomela, T.; Zeviani, M.; Chung, J.; et al. Expression of the Ciona intestinalis alternative oxidase (AOX) in Drosophila complements defects in mitochondrial oxidative phosphorylation. Cell Metab. 2009, 9, 449-460. [CrossRef] [PubMed]

64. Hoefnagel, M.H.; Wiskich, J.T. Activation of the plant alternative oxidase by high reduction levels of the Q-pool and pyruvate. Arch. Biochem. Biophys. 1998, 355, 262-270. [CrossRef] [PubMed]

65. de Vries, S.; Grivell, L.A. Purification and characterization of a rotenone-insensitive NADH:Q6 oxidoreductase from mitochondria of Saccharomyces cerevisiae. Eur. J. Biochem. 1988, 176, 377-384. [CrossRef] [PubMed]

66. Szibor, M.; Dhandapani, P.K.; Dufour, E.; Holmstrom, K.M.; Zhuang, Y.; Salwig, I.; Wittig, I.; Heidler, J.; Gizatullina, Z.; Gainutdinov, T.; et al. Broad AOX expression in a genetically tractable mouse model does not disturb normal physiology. Dis. Models Mech. 2017, 10, 163-171. [CrossRef] [PubMed]

67. Saari, S.; Andjelkovic, A.; Garcia, G.S.; Jacobs, H.T.; Oliveira, M.T. Expression of Ciona intestinalis AOX causes male reproductive defects in Drosophila melanogaster. BMC Dev. Biol. 2017, 17, 9. [CrossRef] [PubMed]

68. Hoffman, D.L.; Salter, J.D.; Brookes, P.S. Response of mitochondrial reactive oxygen species generation to steady-state oxygen tension: Implications for hypoxic cell signaling. Am. J. Physiol. Heart Circ. Physiol. 2007, 292, H101-H108. [CrossRef] [PubMed] 
69. Kang, P.T.; Chen, C.L.; Lin, P.; Chilian, W.M.; Chen, Y.R. Impairment of pH gradient and membrane potential mediates redox dysfunction in the mitochondria of the post-ischemic heart. Basic Res. Cardiol. 2017, 112, 36. [CrossRef] [PubMed]

70. Brand, M.D.; Goncalves, R.L.; Orr, A.L.; Vargas, L.; Gerencser, A.A.; Borch Jensen, M.; Wang, Y.T.; Melov, S.; Turk, C.N.; Matzen, J.T.; et al. Suppressors of Superoxide-H2O2 Production at Site IQ of Mitochondrial Complex I Protect against Stem Cell Hyperplasia and Ischemia-Reperfusion Injury. Cell Metab. 2016, 24, 582-592. [CrossRef] [PubMed]

71. Kotlyar, A.B.; Vinogradov, A.D. Slow active/inactive transition of the mitochondrial NADH-ubiquinone reductase. Biochim. Biophys. Acta 1990, 1019, 151-158. [CrossRef]

72. Babot, M.; Birch, A.; Labarbuta, P.; Galkin, A. Characterisation of the active/de-active transition of mitochondrial complex I. Biochim. Biophys. Acta 2014, 1837, 1083-1092. [CrossRef] [PubMed]

73. Gorenkova, N.; Robinson, E.; Grieve, D.J.; Galkin, A. Conformational change of mitochondrial complex I increases ROS sensitivity during ischemia. Antioxid. Redox Signal. 2013, 19, 1459-1468. [CrossRef] [PubMed]

74. Stepanova, A.; Konrad, C.; Guerrero-Castillo, S.; Manfredi, G.; Vannucci, S.; Arnold, S.; Galkin, A. Deactivation of mitochondrial complex I after hypoxia-ischemia in the immature brain. J. Cereb. Blood Flow Metab. Off. J. Int. Soc. Cereb. Blood Flow Metab. 2018. [CrossRef] [PubMed]

75. Treberg, J.R.; Quinlan, C.L.; Brand, M.D. Evidence for two sites of superoxide production by mitochondrial NADH-ubiquinone oxidoreductase (complex I). J. Biol. Chem. 2011, 286, 27103-27110. [CrossRef] [PubMed]

76. Orr, A.L.; Ashok, D.; Sarantos, M.R.; Shi, T.; Hughes, R.E.; Brand, M.D. Inhibitors of ROS production by the ubiquinone-binding site of mitochondrial complex I identified by chemical screening. Free Radic. Biol. Med. 2013, 65, 1047-1059. [CrossRef]

77. Detaille, D.; Pasdois, P.; Semont, A.; Dos Santos, P.; Diolez, P. An old medicine as a new drug to prevent mitochondrial complex I from producing oxygen radicals. PLoS ONE 2019, 14, e0216385. [CrossRef]

78. Mohsin, A.A.; Chen, Q.; Quan, N.; Rousselle, T.; Maceyka, M.W.; Samidurai, A.; Thompson, J.; Hu, Y.; Li, J.; Lesnefsky, E.J. Mitochondrial Complex I Inhibition by Metformin Limits Reperfusion Injury. J. Pharmacol. Exp. Ther. 2019, 369, 282-290. [CrossRef]

79. Xie, D.; Hou, F.F.; Fu, B.L.; Zhang, X.; Liang, M. High level of proteinuria during treatment with renin-angiotensin inhibitors is a strong predictor of renal outcome in nondiabetic kidney disease. J. Clin. Pharmacol. 2011, 51, 1025-1034. [CrossRef]

80. Steinhubl, S.R. Why have antioxidants failed in clinical trials? Am. J. Cardiol. 2008, 101, S14-S19. [CrossRef]

81. Shuaib, A.; Lees, K.R.; Lyden, P.; Grotta, J.; Davalos, A.; Davis, S.M.; Diener, H.C.; Ashwood, T.; Wasiewski, W.W.; Emeribe, U.; et al. NXY-059 for the treatment of acute ischemic stroke. N. Engl. J. Med. 2007, 357, 562-571. [CrossRef] [PubMed]

82. Ganote, C.E.; Armstrong, S.C. Effects of CCCP-induced mitochondrial uncoupling and cyclosporin A on cell volume, cell injury and preconditioning protection of isolated rabbit cardiomyocytes. J. Mol. Cell. Cardiol. 2003, 35, 749-759. [CrossRef]

83. Brennan, J.P.; Berry, R.G.; Baghai, M.; Duchen, M.R.; Shattock, M.J. FCCP is cardioprotective at concentrations that cause mitochondrial oxidation without detectable depolarisation. Cardiovasc. Res. 2006, 72, 322-330. [CrossRef] [PubMed]

84. Geisler, J.G.; Marosi, K.; Halpern, J.; Mattson, M.P. DNP, mitochondrial uncoupling, and neuroprotection: A little dab'll do ya. Alzheimer's Dement. J. Alzheimer's Assoc. 2017, 13, 582-591. [CrossRef] [PubMed]

85. Lopez-Barneo, J.; Ortega-Saenz, P.; Gonzalez-Rodriguez, P.; Fernandez-Aguera, M.C.; Macias, D.; Pardal, R.; Gao, L. Oxygen-sensing by arterial chemoreceptors: Mechanisms and medical translation. Mol. Asp. Med. 2016, 47-48, 90-108. [CrossRef]

86. Salvati, K.A.; Beenhakker, M.P. Out of thin air: Hyperventilation-triggered seizures. Brain Res. 2019, 1703, 41-52. [CrossRef]

87. Wyatt, C.N.; Buckler, K.J. The effect of mitochondrial inhibitors on membrane currents in isolated neonatal rat carotid body type I cells. J. Physiol. 2004, 556, 175-191. [CrossRef]

88. McElroy, G.S.; Chandel, N.S. Mitochondria control acute and chronic responses to hypoxia. Exp. Cell Res. 2017, 356, 217-222. [CrossRef]

89. Dunham-Snary, K.J.; Wu, D.; Potus, F.; Sykes, E.A.; Mewburn, J.D.; Charles, R.L.; Eaton, P.; Sultanian, R.A.; Archer, S.L. Ndufs2, a Core Subunit of Mitochondrial Complex I, Is Essential for Acute Oxygen-Sensing and Hypoxic Pulmonary Vasoconstriction. Circ. Res. 2019, 124, 1727-1746. [CrossRef] 
90. Yoo, S.Z.; No, M.H.; Heo, J.W.; Park, D.H.; Kang, J.H.; Kim, J.H.; Seo, D.Y.; Han, J.; Jung, S.J.; Kwak, H.B. Effects of Acute Exercise on Mitochondrial Function, Dynamics, and Mitophagy in Rat Cardiac and Skeletal Muscles. Int. Neurourol. J. 2019, 23, S22-S31. [CrossRef]

91. Xie, K.; Ngo, S.; Rong, J.; Sheppard, A. Modulation of mitochondrial respiration underpins neuronal differentiation enhanced by lutein. Neural Regen. Res. 2019, 14, 87-99. [CrossRef] [PubMed]

92. Sanz, A.; Soikkeli, M.; Portero-Otin, M.; Wilson, A.; Kemppainen, E.; McIlroy, G.; Ellila, S.; Kemppainen, K.K.; Tuomela, T.; Lakanmaa, M.; et al. Expression of the yeast NADH dehydrogenase Ndi1 in Drosophila confers increased lifespan independently of dietary restriction. Proc. Natl. Acad. Sci. USA 2010, 107, 9105-9110. [CrossRef]

93. Bahadorani, S.; Cho, J.; Lo, T.; Contreras, H.; Lawal, H.O.; Krantz, D.E.; Bradley, T.J.; Walker, D.W. Neuronal expression of a single-subunit yeast NADH-ubiquinone oxidoreductase (Ndi1) extends Drosophila lifespan. Aging Cell 2010, 9, 191-202. [CrossRef] [PubMed]

94. DeCorby, A.; Gaskova, D.; Sayles, L.C.; Lemire, B.D. Expression of Ndi1p, an alternative NADH:ubiquinone oxidoreductase, increases mitochondrial membrane potential in a C. elegans model of mitochondrial disease. Biochim. Biophys. Acta 2007, 1767, 1157-1163. [CrossRef] [PubMed]

95. Cossard, R.; Esposito, M.; Sellem, C.H.; Pitayu, L.; Vasnier, C.; Delahodde, A.; Dassa, E.P. Caenorhabditis elegans expressing the Saccharomyces cerevisiae NADH alternative dehydrogenase Ndi1p, as a tool to identify new genes involved in complex I related diseases. Front. Genet. 2015, 6, 206. [CrossRef] [PubMed]

96. Acin-Perez, R.; Enriquez, J.A. The function of the respiratory supercomplexes: The plasticity model. Biochim. Biophys. Acta 2014, 1837, 444-450. [CrossRef] [PubMed]

97. Lapuente-Brun, E.; Moreno-Loshuertos, R.; Acin-Perez, R.; Latorre-Pellicer, A.; Colas, C.; Balsa, E.; Perales-Clemente, E.; Quiros, P.M.; Calvo, E.; Rodriguez-Hernandez, M.A.; et al. Supercomplex assembly determines electron flux in the mitochondrial electron transport chain. Science 2013, 340, 1567-1570. [CrossRef]

98. Jones, D.P.; Sies, H. The Redox Code. Antioxid. Redox Signal. 2015, 23, 734-746. [CrossRef]

99. Trewin, A.J.; Bahr, L.L.; Almast, A.; Berry, B.J.; Wei, A.Y.; Foster, T.H.; Wojtovich, A.P. Mitochondrial Reactive Oxygen Species Generated at the Complex-II Matrix or Intermembrane Space Microdomain Have Distinct Effects on Redox Signaling and Stress Sensitivity in Caenorhabditis elegans. Antioxid. Redox Signal. 2019, 31, 594-607. [CrossRef] 